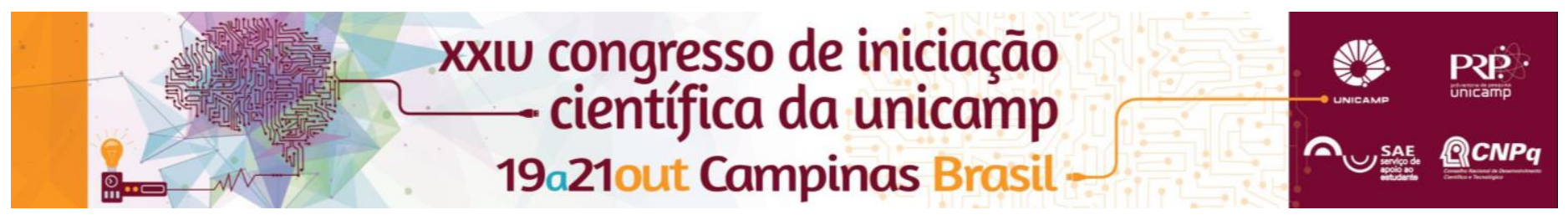

\title{
Estudo e implementação de um sistema Hardware-in-the-Loop
}

\section{Eduardo M. Coraça*, Janito V. Ferreira}

\section{Resumo}

Neste trabalho a técnica Hardware-in-the-loop é estudada, a qual consiste no estudo do comportamento dinâmico de um sistema a partir da simulação conjunta de dois subsistemas: um numérico e um físico. O teste foi realizado em um sistema massa-mola-amortecedor, sendo a mola física e a massa e o amortecedor matemáticos, cujos efeitos do atraso temporal existente no sistema foram discutidos. Métodos para sua correção foram analisados.

\section{Palavras-chave:}

Hardware-in-the-Loop, Simulação, Tempo Real.

\section{Introdução}

Simulações computacionais são extensivamente utilizadas na fase de desenvolvimento de novas tecnologias, porém alguns elementos podem ser muito complexos para serem modelados matematicamente. Em contrapartida, a utilização de modelos em escala real pode ser economicamente inviável. Neste cenário, a técnica Hardware-in-the-Loop (HiL) pode ser empregada, a qual consiste na segmentação do dispositivo de interesse em duas partes: uma física (hardware), contendo os componentes de alta complexidade, e outra modelada numericamente (software). O grande problema presente neste método é a presença de um atraso temporal na malha fechada.

Neste trabalho uma simulação HiL é implementada em um sistema massa-mola-amortecedor, utilizando a mola como hardware, como indicado na Figura 1. Dois métodos de correção de atraso já existentes são simulados e um novo método é apresentado e comparado com outros dois. Simulações numéricas e testes experimentais são conduzidos para tal comparação utilizando o programa MATLAB/Simulink juntamente com um atuador hidráulico SCHENCK e placas de aquisição dSPACE.

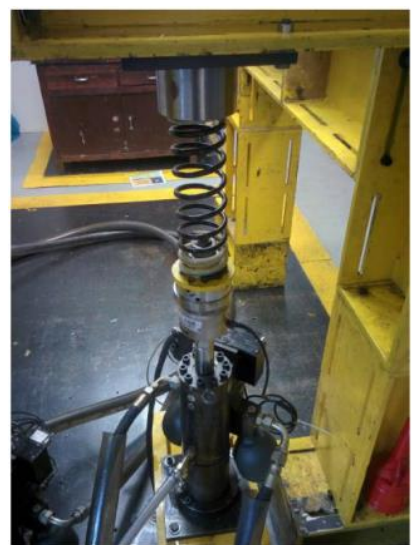

Figura 1. Sistema experimental.

\section{Resultados e Discussão}

A partir de medições experimentais, a curva de resposta em deslocamento da mola para uma dada força foi levantada e um modelo matemático foi ajustado. Já o sistema massa-amortecedor foi modelado no Simulink através de equações de estado. Finalmente, a simulação do teste HiL sem atraso está indicada na Figura 2.

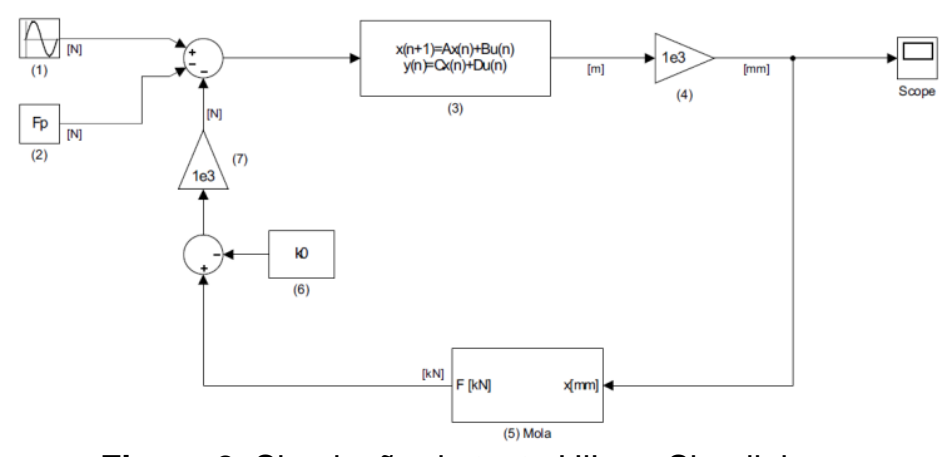

Figura 2. Simulação do teste HiL no Simulink.

Dois métodos para a correção do atraso foram estudados, são eles a Extrapolação Polinomial, que ajusta um polinômio aos deslocamentos calculados com a finalidade de se prever o valor futuro, e a Alteração na Ordem das Operações Discretas, que altera a sequência de operações da placa dSPACE. Um terceiro método foi proposto, baseado em série de Taylor, para a predição do valor futuro.

Utilizando os métodos de correção, diversas simulações foram realizadas. Um dos resultados é indicado na Figura 3.

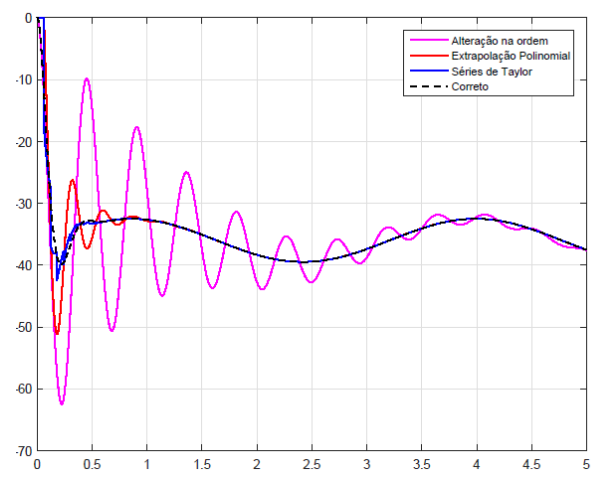

Figura 3. Resultados da simulação.

\section{Conclusões}

A técnica HiL foi estudada, simulada e implementada experimentalmente com sucesso. Um atraso temporal foi identificado e suas consequências foram analisadas do ponto de vista de controle. Métodos para a sua correção foram analisados e um novo método foi proposto. Os resultados das simulações foram validados através de experimentos. 